\title{
Angiotensin II type 1 receptor inhibition markedly improves the blood perfusion, oxygen tension and first phase of glucose-stimulated insulin secretion in revascularised syngeneic mouse islet grafts
}

Received: 4 January 2005 / Accepted: 5 February 2005 / Published online: 5 May 2005

(C) Springer-Verlag 2005

\begin{abstract}
Aims/hypothesis: We recently found evidence of an angiotensin-generating system in pancreatic islets. The present study investigated the effect of endogenously produced angiotensin II on microcirculation and function in transplanted islets. Materials and methods: Losartan, an angiotensin II type 1 receptor inhibitor, was administered either acute intravenously to mice with 4-week-old islet renal subcapsular transplants, or added to the drinking water for the final 14 days or throughout the 4-week post-transplantation period. The graft-bearing kidney was, in some cases, dissected out and perfused in vitro to evaluate the effect of angiotensin II and losartan on glucose-stimulated insulin release from the grafts. Results: Losartan treatment throughout the 4-week post-transplantation period had negative effects on islet revascularisation as well as on islet graft insulin release. However, administration of losartan,
\end{abstract}

C. Kampf · T. Lau $\cdot$ R. Olsson · P.-O. Carlsson

Department of Medical Cell Biology,

Uppsala University,

Uppsala, Sweden

C. Kampf

Department of Genetics and Pathology,

Uppsala University,

Uppsala, Sweden

T. Lau $\cdot$ P. S. Leung

Department of Physiology, Faculty of Medicine,

The Chinese University of Hong Kong,

Shatin, Hong Kong

P.-O. Carlsson

Department of Medical Sciences,

Uppsala University,

Uppsala, Sweden

P.-O. Carlsson $(\square)$

Department of Medical Cell Biology,

Biomedical Center,

Husargatan 3, Box 571,

75123 Uppsala, Sweden

e-mail: Per-Ola.Carlsson@medcellbiol.uu.se

Tel.: +46-18-4714425

Fax: +46-18-4714059 either intravenously or orally, after the formation of a new vascular network, improved islet graft blood perfusion. $P_{\mathrm{O} 2}$ in the islet transplants was also effectively improved by the losartan treatment. Graft perfusion experiments showed a markedly better first phase of glucose-stimulated insulin release in transplanted islets when exposed to losartan. In contrast, acute administration of angiotensin II decreased islet graft blood flow, $\mathrm{PO}_{2}$ and glucose-stimulated insulin release. Conclusions/interpretation: This study shows that inhibition of the islet reninangiotensin system may be a feasible strategy to increase the blood perfusion, $\mathrm{PO}_{2}$ and function within islet grafts. Such treatment should not be initiated, however, before the islet vascular system has been formed.

Keywords Angiotensin II - Islet transplantation · Losartan $\cdot$ Reninangiotensin system

Abbreviations $\mathrm{AT}_{1}$ : angiotensin II type $1 \cdot \mathrm{RAS}$ : reninangiotensin system

\section{Introduction}

Modifications of islet allotransplantation protocols, as well as repeated transplantations to increase the implanted endocrine mass, have substantially increased the number of patients given the opportunity to become insulin independent $[1,2]$. However, this concept further accentuates the already troublesome lack of human donors for clinical islet transplantation, and emphasises the need for optimising islet isolation techniques and treatments to ensure maximal survival and function of the grafted islets following transplantation. A potential contributing factor to poor graft function is insufficient or inadequate engraftment of the islets in the implantation organ. Normally, pancreatic islets have a rich blood supply that is almost ten times higher than that in the exocrine pancreas, and similar to that seen in the renal cortex (approx. 5-7 $\mathrm{ml} \cdot \mathrm{min}^{-1} \cdot \mathrm{g}^{-1}$ ) [3]. However, isolation of pancreatic islets for transplantation dis- 
rupts the islet vascular connections. Revascularisation of the transplanted islets is initiated within a few days and concluded within 14 days [4-6]. Nevertheless, blood perfusion and partial pressure of oxygen are chronically decreased in transplanted islets irrespective of implantation organ [7]. A reasonable explanation for the insufficient blood supply was provided in experiments where vascular density was found to be decreased in transplanted islets [8].

However, the vascular system of endogenous islets is not only characterised by a dense glomerular-like angioarchitecture but also a complex regulation of islet blood flow that closely adapts to fit the requirements for hormone secretion [3]. The functional properties of islet graft microvessels have not been described in as much detail. However, our previous studies have indicated that islet grafts may be even more sensitive than native islets to the vasoconstrictive effects of angiotensin II $[9,10]$. Moreover, the presence of a local reninangiotensin system (RAS) in pancreatic islets [11] means that angiotensin II may be formed within islets in high local concentrations. The present study aimed to investigate the effect of endogenously produced angiotensin II on islet microcirculation and function in transplanted islets. For this purpose, losartan, an angiotensin II type $1\left(\mathrm{AT}_{1}\right)$ receptor inhibitor, was administered in one of the following ways: (1) acute intravenously to anaesthetised mice with renal subcapsular islet transplants; (2) added to the drinking water for the final 14 days, i.e. after the formation of a new islet vascular network; or (3) added to the drinking water throughout the 4-week post-transplantation period prior to the study.

\section{Materials and methods}

Animals

Male C57BL/6 mice weighing approximately $30 \mathrm{~g}$ were purchased from M\&B (Ry, Denmark). The animals had free access to tap water and pelleted food throughout the study. All experiments were approved by the animal ethics committee of Uppsala University and followed the 'Principles of laboratory animal care' (NIH publication no. 8523, revised 1985).

Islet isolation, culture and transplantation

Pancreatic islets from $\mathrm{C} 57 \mathrm{BL} / 6$ mice were prepared by collagenase digestion and cultured free-floating for 4-5 days in groups of 150 islets in $5 \mathrm{ml}$ RPMI- 1640 medium supplemented with $11 \mathrm{mmol} / 1$ glucose and $10 \%(\mathrm{v} / \mathrm{v})$ fetal calf serum in $95 \%$ air $/ 5 \% \mathrm{CO}_{2}$ at $37^{\circ} \mathrm{C}$ [12]. The medium was changed every second day. At transplantation, approximately 200 islets were packed in a braking pipette and implanted beneath the renal capsule of the left kidney in avertin-anaesthetised mice $(0.02 \mathrm{ml} / \mathrm{g}$ i.p. of a $2.5 \%$ [v/v] solution of $10 \mathrm{~g}$ 97\% 2,2,2-tribromoethanol [Sigma, St
Louis, MO, USA] in $10 \mathrm{ml}$ 2-methyl-2-butanol [Kemila, Stockholm, Sweden]).

\section{Chronic losartan treatment}

Some of the transplanted mice were randomly assigned to treatment with losartan $\left(30 \mathrm{mg} \cdot \mathrm{kg}^{-1} \cdot \mathrm{day}^{-1}\right.$; Merck \& Co, Whitehouse Station, NJ, USA) dissolved in the drinking water. The concentration of losartan in drinking water $(0.13$ $\mathrm{mg} / \mathrm{ml}$ ) to yield this dose of losartan was determined by pilot experiments $(n=3)$ where the daily intake of water averaged $7 \mathrm{ml}$ for each mouse during a 1-week period.

\section{Oxygen tension and blood flow measurements}

Four weeks after transplantation, some of the transplanted animals and some control (non-transplanted) animals were anaesthetised with avertin $(0.02 \mathrm{ml} / \mathrm{g}$ i.p. $)$, placed on an operating table maintained at $37^{\circ} \mathrm{C}$, and surgically prepared for islet oxygen tension and blood flow measurements, as previously described $[13,14]$.

Oxygen tension was measured in the endogenous and transplanted islets as well as in the surrounding tissues using modified Clark-type microelectrodes [14]. The electrodes (tip outer diameter 2-6 $\mu \mathrm{m}$ ) were inserted into the tissues using a micromanipulator. At least ten measurements of $\mathrm{PO}_{2}$ were taken from the transplanted islets and surrounding renal parenchyma in each animal. In the pancreata of control animals, measurements were performed in three to five superficial pancreatic islets and the surrounding exocrine parenchyma. Multiple measurements were usually performed within the same islet; the mean was calculated to obtain the $\mathrm{PO}_{2}$ value for one islet. The mean of all measurements in each tissue and animal was calculated and considered to be one experiment. Measurements of oxygen tension in transplanted islets were in some cases performed before and $10 \mathrm{~min}$ after an intravenous injection of losartan $(10 \mathrm{mg} / \mathrm{kg}$ body weight; Merck \& Co.), or before and after a 10-min infusion of angiotensin II (10 ng/min; Sigma).

In conjunction with the oxygen tension measurements, the blood perfusion of the islet graft and the adjacent renal cortex was measured by laser-Doppler flowmetry (PF40012; Perimed, Stockholm, Sweden) using a needle probe (411; tip outside diameter $0.45 \mathrm{~mm}$; Perimed). The flow probe was positioned perpendicular to the immobilised tissue surface using a micromanipulator, and care was taken not to cause any compression of the tissue. At least four blood flow measurements were performed in the transplanted islets and renal cortex in each animal both before and after administration of losartan or angiotensin II (see above section). The mean of these measurements from each animal was calculated and considered to be one experiment. All blood flow values are given as arbitrary tissue perfusion units, as it is difficult to calibrate the instrument in physical units of blood flow. The blood perfusion of endogenous islets cannot be determined by laser-Doppler 
flowmetry because of their small size. During the oxygen tension and blood flow measurements, blood pressure, body temperature and tissue temperature were continuously recorded using a MacLab Instrument (AD Instruments, Hastings, UK). All measurements of oxygen tension and blood perfusion were, for obvious technical reasons, only performed at one time point in each experimental animal.

\section{Measurements of blood parameters}

Blood glucose concentrations were determined using test reagent strips (Medisense, Baxter Travenol, Deerfield, IL, USA) from samples obtained from the cut tip of the tail. At the end of the blood flow and oxygen tension measurements, a blood sample was collected for analysis of haematocrit and blood gases. Haematocrit lower than 40, pH lower than 7.30, $\mathrm{PO}_{2}$ lower than $10 \mathrm{kPa}$, or $\mathrm{PCO}_{2}$ higher than $6.8 \mathrm{kPa}$ were used as exclusion criteria, which led to the exclusion of one animal from the study owing to $\mathrm{CO}_{2}$ retention.

\section{Light microscopic evaluation}

The graft-bearing left kidneys, or pancreata from control animals, were removed after the oxygen tension and blood flow measurements, fixed in $10 \%(\mathrm{v} / \mathrm{v})$ formaldehyde and embedded in paraffin. Sections $(5 \mu \mathrm{m}$ thick) of the islet grafts and pancreata were prepared and stained with the lectin Bandeiraea simplicifolia (Sigma) [8]. The slides were counterstained with haematoxylin. For each animal, ten or more tissue sections from all parts of the pancreas, or islet transplants stained with Bandeiraea simplicifolia, were randomly chosen and evaluated. The number of stained blood vessels in endogenous and transplanted islets was quantified using a light microscope (magnification $\times 100$ ). In the islet grafts, connective tissue surrounded the individual islets in the grafts. The blood vessels in the endocrine and connective tissues were therefore counted separately. The fraction of the islet grafts composed of endocrine tissue was measured by a direct point-counting method. The intersections overlapping connective tissue stroma and endocrine cells within the islet grafts were counted at a magnification of $\times 100$ using a light microscope. The area of the investigated endogenous and grafted islets was determined using a computerised system for morphometry (Easy image 3000; Tekno Optik, Huddinge, Sweden). Vascular density, i.e. the number of stained blood vessels found per measured islet or graft area $\left(\mathrm{mm}^{2}\right)$, was then calculated.

Islet graft perfusion

Grafts from some of the transplanted animals were investigated 4 weeks after transplantation for glucose-stimulated insulin secretion using a previously published protocol [15]. Briefly, the graft-bearing left kidney was removed together with part of the aorta and inferior vena cava. The ureter and the renal vein were cut, while the aorta was cannulated and infused with a continuously gassed $\left(\mathrm{O}_{2}\right.$ : $\left.\mathrm{CO}_{2}=95: 5\right)$ Krebs-Ringer bicarbonate buffer supplemented with $2.0 \%(\mathrm{w} / \mathrm{v})$ of each of BSA (fraction V; Miles Laboratories, Slough, UK) and dextran T70 (Pharmacia, Uppsala, Sweden) as well as with 2.8 or $16.7 \mathrm{mmol} / \mathrm{l}$ glucose respectively. The medium was administered at a rate of 1.0 $\mathrm{ml} / \mathrm{min}$ without recycling for $60 \mathrm{~min}$ with a perfusion pressure of approximately $40 \mathrm{mmHg}$. The perfusion experiments started with a 15 -min period using a medium containing $2.8 \mathrm{mmol} / \mathrm{l}$ glucose, followed by $30 \mathrm{~min}$ using 16.7 $\mathrm{mmol} / \mathrm{l}$ glucose and $15 \mathrm{~min}$ using $2.8 \mathrm{mmol} / \mathrm{l}$ glucose. In some experiments, angiotensin II (Sigma) or losartan (Merck) was added during the perfusion with the highglucose medium $(16.7 \mathrm{mmol} / \mathrm{l})$ at a concentration of $10 \mathrm{ng} /$ $\mathrm{ml}$ or $100 \mu \mathrm{g} / \mathrm{ml}$ respectively. A $1.0-\mathrm{ml}$ sample of the effluent medium was collected every fifth minute, except during the first 10 min of perfusion with the high glucose concentration, when samples were taken after 1, 2, 3, 4, 5, 7 and $10 \mathrm{~min}$. The insulin concentrations of the effluent samples were measured by ELISA (Mercodia, Uppsala, Sweden). The rate of insulin secretion was calculated by multiplying the insulin concentration in the sample by the flow rate, giving values of insulin expressed as $\mathrm{ng} / \mathrm{min}$.

\section{Insulin contents of the islet grafts}

After perfusion the graft was removed from the kidney and homogenised in $1,000 \mu \mathrm{l}$ of acid-ethanol $(0.18 \mathrm{mmol} / \mathrm{l} \mathrm{HCl}$ in $95 \%[\mathrm{v} / \mathrm{v}]$ ethanol). The samples were extracted overnight at $4{ }^{\circ} \mathrm{C}$, followed by ELISA of the insulin (Mercodia).

\section{Islet graft (pro)insulin and total protein biosynthesis}

Four weeks after transplantation, some of the transplanted animals were allocated for measurement of islet graft (pro) insulin and total protein biosynthesis, as previously described [15]. Briefly, explanted islet grafts were incubated with or without $1 \mu \mathrm{mol} / 1$ losartan (Merck) at $37^{\circ} \mathrm{C}$ in $100 \mu \mathrm{l}$ of Krebs-Ringer bicarbonate HEPES buffer containing $1.85 \mathrm{MBq} / \mathrm{ml}$ of $\mathrm{L}-\left[4,5,{ }^{-3} \mathrm{H}\right]$ leucine (Amersham-Pharmacia Biotech, Uppsala, Sweden) and $16.7 \mathrm{mmol} / \mathrm{l}$ glucose in an atmosphere of humidified air plus $5 \% \mathrm{CO}_{2}$. After $2 \mathrm{~h}$, the islets were washed in buffer containing non-radioactive leucine $(10 \mathrm{mmol} / \mathrm{l})$ and sonicated in $200 \mu \mathrm{l}$ of redistilled water. The amount of labelled (pro)insulin was determined by an immunoadsorption technique [16] and the total protein biosynthesis was measured in trichloroacetic acid precipitates of islet homogenates.

\section{Statistical analysis}

All values are given as means \pm SEM. When multiple comparisons between data were performed, one-way ANOVA and Bonferronni's post-hoc test were applied. For pairwise 
comparisons, Student's $t$-test was used. For all comparisons, a $p$ value of less than 0.05 was considered statistically significant.

\section{Results}

Mean arterial blood pressure and blood glucose concentrations

Data are shown in Table 1. All non-pretreated animals allocated to studies of blood flow and oxygen tension had a mean arterial pressure of $100-110 \mathrm{mmHg}$. Acute intravenous administration of angiotensin II increased blood pressure by approximately $25 \%$, while acute intravenous or daily oral losartan treatment decreased the blood pressure to between 80 and $90 \mathrm{mmHg}$. Blood glucose concentrations were similar in all animals and were not affected by angiotensin II or losartan treatment.

\section{Blood flow in islet grafts and the renal cortex}

Data are shown in Fig. 1. Before treatment, the blood perfusion of the islet grafts was approximately $33 \%$ of that of the renal cortex in all animals. Acute intravenous administration of angiotensin II decreased the blood perfusion by approximately $30 \%$ in the islet grafts and the renal cortex. Acute intravenous losartan administration increased islet graft blood flow by $175 \pm 37 \%(n=6)$ but renal cortical blood flow by only $75 \pm 10 \%(n=6)(p<0.05)$. Thus, after acute losartan treatment, islet graft blood flow was approximately $50 \%$ of that in the renal cortex. Losartan added to the drinking water throughout the 4-week post-transplantation period did not affect islet graft blood flow or renal cortical blood flow. In contrast, when administered orally during the final 14 days, i.e. after the formation of a new vascular network, islet graft and renal blood perfusion were increased to a similar extent to that seen following acute intravenous treatment.

Oxygen tension in islet grafts and the renal cortex

Data are shown in Fig. 2. Oxygen tension in the 4-week-old islet transplants was, in all cases, lower than $10 \mathrm{mmHg}$ in

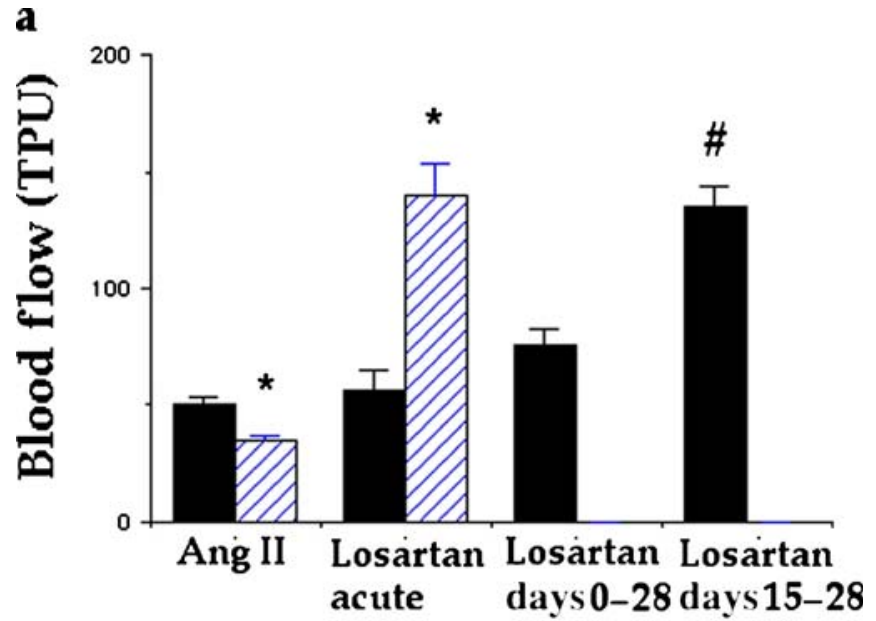

b

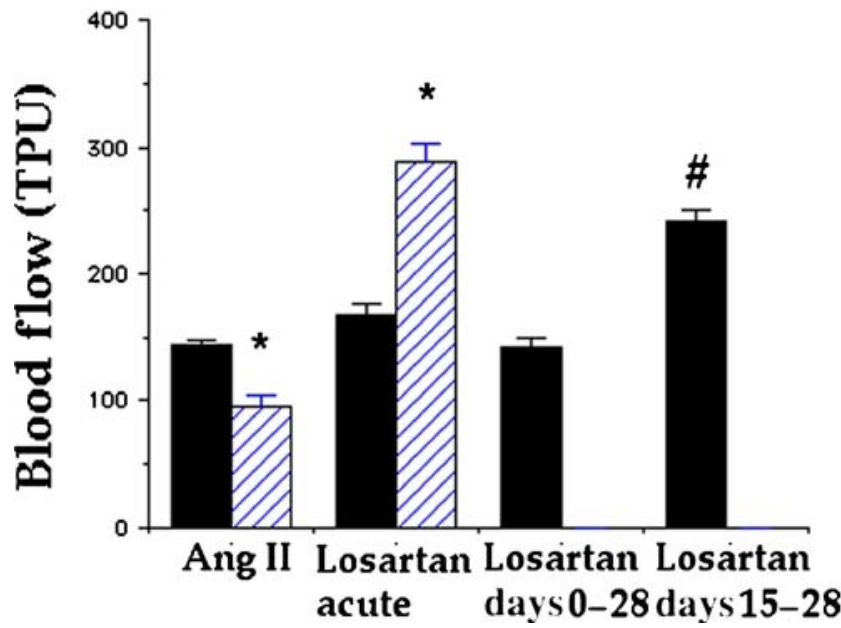

Fig. 1 Effect of intravenous infusion of angiotensin II (Ang II; 10 $\mathrm{ng} / \mathrm{min}$ ), intravenous injection of the angiotensin II type 1 receptor inhibitor losartan $(10 \mathrm{mg} / \mathrm{kg}$; acute $)$ and oral treatment with losartan $\left(30 \mathrm{mg} \cdot \mathrm{kg}^{-1} \cdot \mathrm{day}^{-1}\right)$ dissolved in the drinking water throughout the post-transplantation period (days 0-28) or for the final 14 days (days 15-28) on blood flow in islet graft (a) and adjacent renal cortex (b) in $\mathrm{C} 57 \mathrm{B1} / 6$ mice 4 weeks after transplantation. Closed and hatched bars show results before and after intravenous injections respectively. Please note the different scales on the ordinates in (a) and (b). All values are means \pm SEM for six to eight animals. ${ }^{*} p<0.05$ vs before treatment; ${ }^{\sharp} p<0.05$ vs non-pretreated transplanted animals. Values from the groups 'before acute angiotensin II' and 'before acute losartan treatment' were pooled when used as control for the orally treated losartan groups. All comparisons were made using ANOVA. TPU Tissue perfusion units

Table 1 Mean arterial blood pressure (MAP) and blood glucose concentrations in non-transplanted and islet-transplanted C57BL/6 mice allocated to studies of islet blood flow and oxygen tension

\begin{tabular}{|c|c|c|c|c|c|c|c|}
\hline & \multirow[t]{3}{*}{ Non-transplanted animals } & \multicolumn{6}{|c|}{ Transplanted animals } \\
\hline & & \multicolumn{2}{|c|}{ Angiotensin II } & \multicolumn{2}{|l|}{ Losartan } & \multicolumn{2}{|c|}{ Losartan pretreatment } \\
\hline & & Before & After & Before & After & Days $0-28$ & Days $15-28$ \\
\hline MAP (mmHg) & $99 \pm 7$ & $98 \pm 3$ & $124 \pm 4^{\mathrm{a}}$ & $112 \pm 3$ & $89 \pm 2^{\mathrm{a}}$ & $88 \pm 3^{\mathrm{a}}$ & $82 \pm 2^{\mathrm{a}}$ \\
\hline Blood glucose (mmol/l) & $7.2 \pm 0.1$ & $7.2 \pm 0.2$ & $7.0 \pm 0.4$ & $6.9 \pm 0.1$ & $6.7 \pm 0.1$ & $7.3 \pm 0.4$ & $7.2 \pm 0.3$ \\
\hline
\end{tabular}

All values are the means \pm SEM for six to eight animals in each group

All comparisons were made using ANOVA and Bonferroni's posthoc test

${ }^{\mathrm{a}} p<0.05$ vs the corresponding untreated animals 


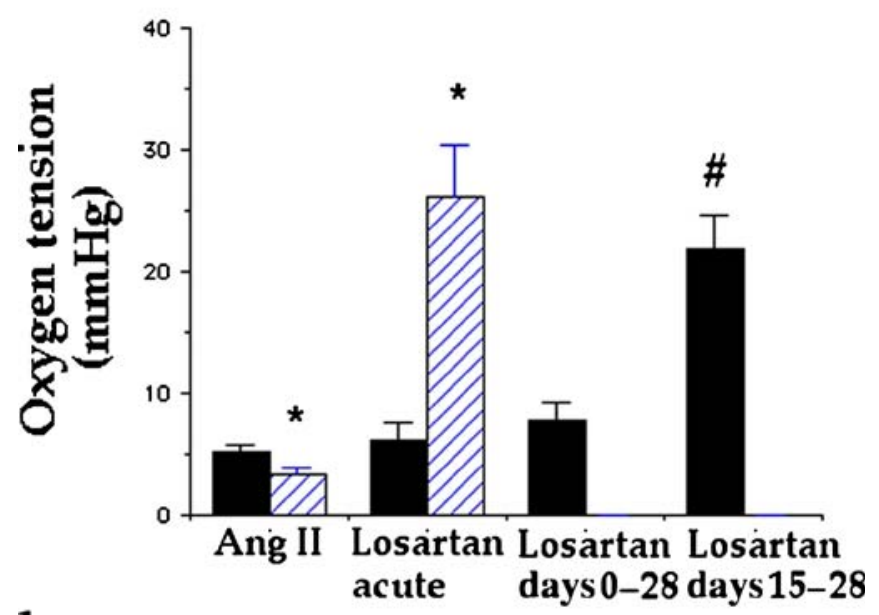

b

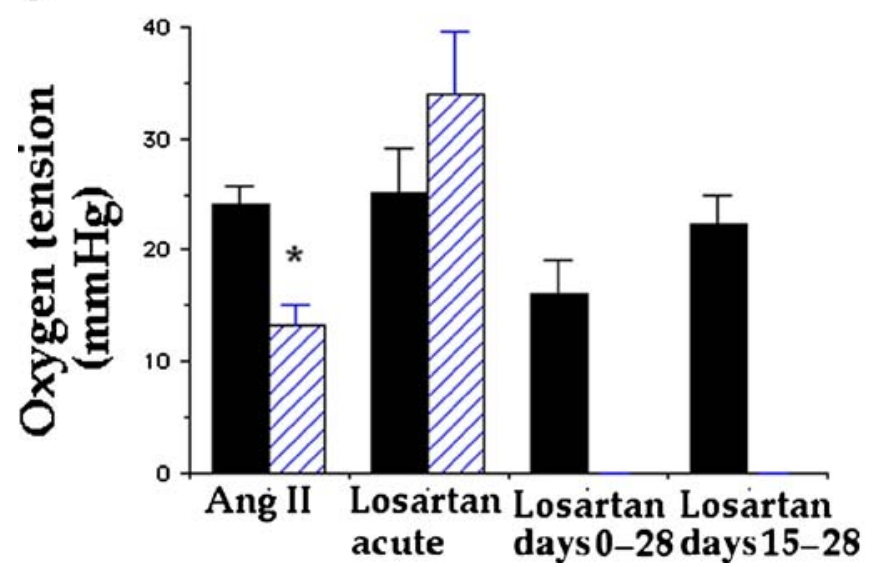

Fig. 2 Effect of intravenous infusion of angiotensin II (Ang II; 10 $\mathrm{ng} / \mathrm{min}$ ), intravenous injection of the angiotensin II type 1 receptor inhibitor losartan $(10 \mathrm{mg} / \mathrm{kg}$; acute) and oral treatment with losartan $\left(30 \mathrm{mg} \mathrm{kg}^{-1}\right.$ day $\left.^{-1}\right)$ dissolved in the drinking water throughout the post-transplantation period (days 0-28) or for the final 14 days (days 15-28) on oxygen tension in islet graft (a) and adjacent renal cortex (b) in C57BL/6 mice 4 weeks after transplantation. Closed and hatched bars show results before and after intravenous injections respectively. All values are means \pm SEM for six to eight animals. ${ }^{*} p<0.05$ vs before treatment; ${ }^{\#} p<0.05$ vs non-pretreated transplanted animals. Values from the groups 'before acute angiotensin II' and 'before acute losartan treatment' were pooled when used as control for the orally treated losartan groups. All comparisons were made using ANOVA

untreated animals (Fig. 2a) and therefore in less than 20\% of values in native islets $(44.3 \pm 2.5 \mathrm{mmHg} ; n=6)$. Acute intravenous administration of angiotensin II decreased the oxygen tension levels in both the islet grafts and the adjacent renal cortex. Acute intravenous losartan treatment markedly improved the $P_{\mathrm{O} 2}$ in the islet transplants. Oxygen tension in the renal cortex also tended to be slightly increased after acute losartan treatment, but this increase was not statistically significant $(p=0.27)$. Chronic losartan treatment throughout the 4-week period following transplantation had no effect on the oxygen tension in the islet grafts or the renal cortex. However, when losartan was administered orally during the final 14 days prior to measurements, the
$P_{\mathrm{O} 2}$ in the islet transplants was improved while renal cortical $P_{\mathrm{O} 2}$ was unaffected.

Vascular density

Data are shown in Figs 3 and 4. The vascular density in the transplanted islets of untreated animals, and of animals treated orally with losartan for the final 14 days, was 20 $25 \%$ of that in native islets. Individual islets in the grafts, however, were surrounded by connective tissue stroma with a high number of capillaries. The total islet graft vascular density, i.e. the combined vascular density of the connective and endocrine compartments of the grafts, was therefore similar to that in native islets. Losartan treatment throughout the post-transplantation period, also including the revascularisation phase, selectively decreased the vascular density in the endocrine parts of the grafts. Oral losartan treatment also decreased the connective tissue percentage in the islet grafts from $36.9 \pm 3.2 \%(n=8)$ to $21.6 \pm$ $3.3 \%(n=7$; treatment throughout the post-transplantation period $)$ and $13.5 \pm 1.4 \%(n=7$; treatment for the final 14 days $)$ $(p<0.05$ for both comparisons vs control). As there was less connective tissue in the islet grafts obtained from animals treated with losartan for the final 14 days before study, the total islet graft vascular density in these grafts was lower than in control grafts.

Graft insulin release and insulin contents

Data on graft insulin release are shown in Fig. 5. A firstphase insulin release in response to a high glucose stim-

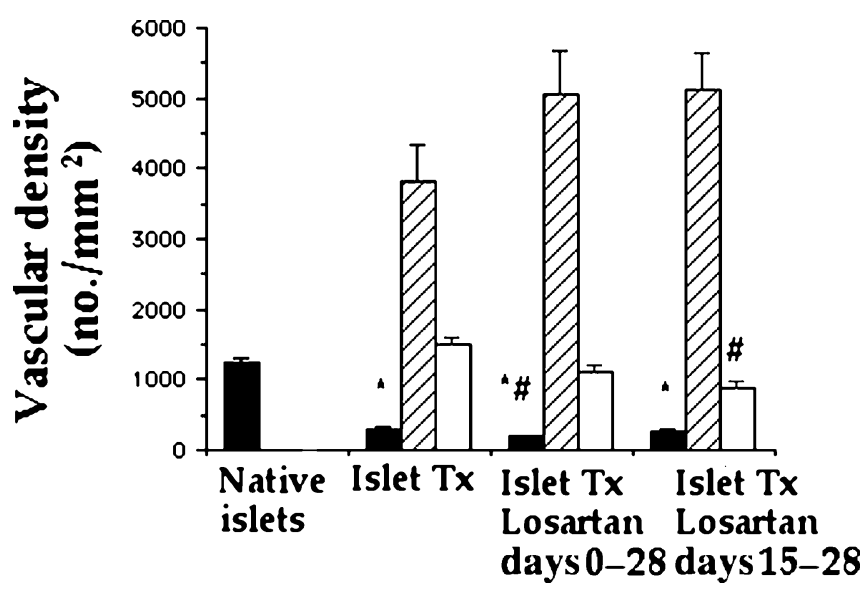

Fig. 3 Vascular density in native mouse pancreatic islets and in islet grafts 4 weeks after transplantation beneath the renal capsule of syngeneic C57BL/6 mice. Some of the transplanted animals were subjected to treatment with the angiotensin II type 1 receptor inhibitor losartan $\left(30 \mathrm{mg} \cdot \mathrm{kg}^{-1} \cdot \mathrm{day}^{-1}\right)$ dissolved in the drinking water throughout the 4-week post-transplantation period (days 0-28) or for the final 14 days (days 15-28). Values are given for the endocrine tissue (closed bars), the connective tissue stroma (hatched bars) and the whole islet graft (empty bars). All values are means \pm SEM for six to eight animals. ${ }^{*} p<0.05$ vs native pancreatic islets; ${ }^{\#} p<0.05$ vs endocrine tissue in control islet grafts. All comparisons were made using ANOVA. $T x$ Transplant 
a

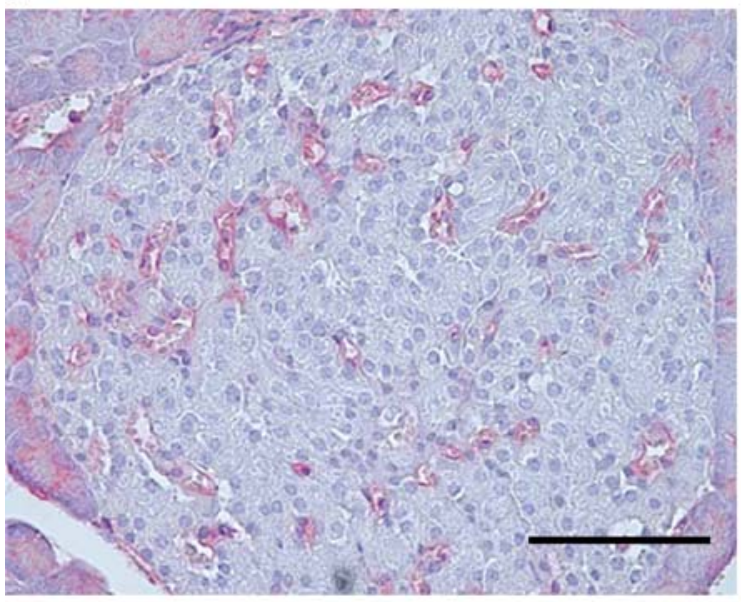

C

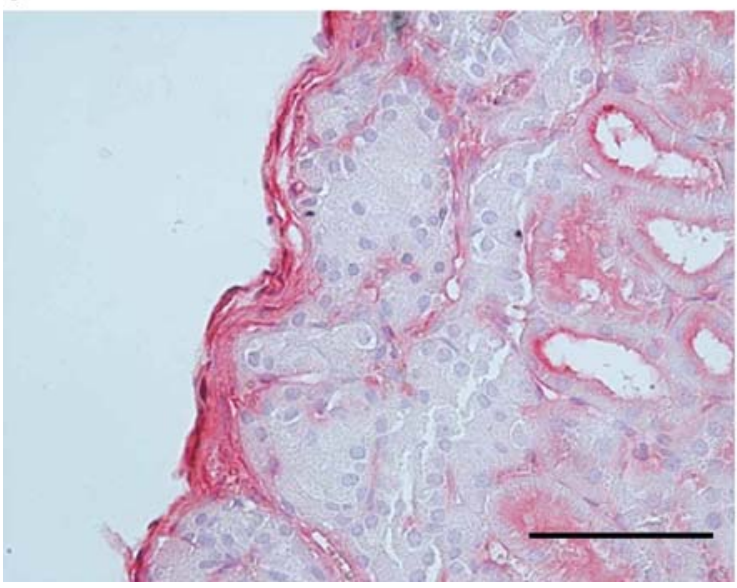

Fig. 4 Micrographs of native pancreatic islet (a) and 4-week-old islet grafts retrieved from untreated animals (b) or from animals treated with losartan throughout the post-transplantation period (c) b

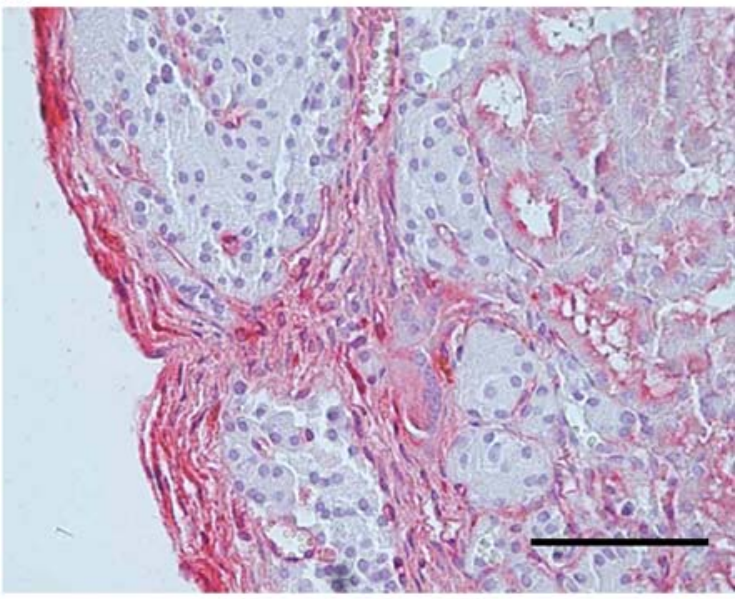

d

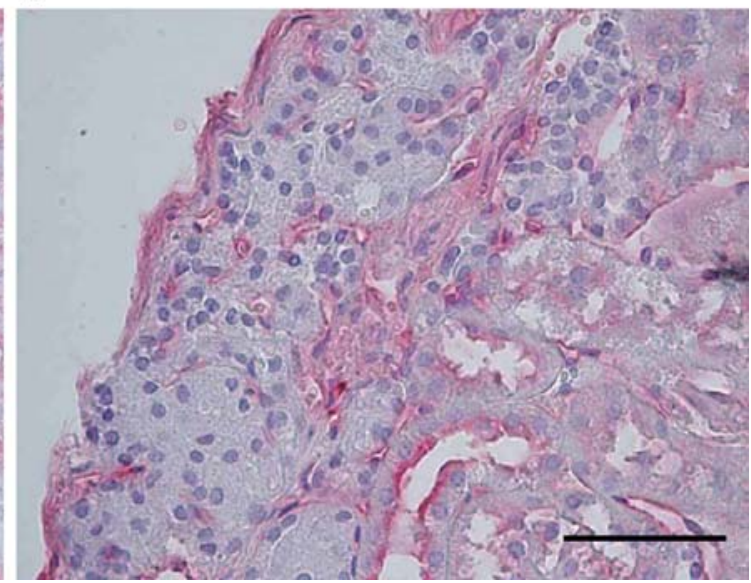

or for the final 14 days (d). All tissues were stained with the lectin Bandeirae simplicifolia (red) to visualise blood vessels within the pancreatic islets. Scale bar $=50 \mu \mathrm{m}$ ulation (15-20 $\mathrm{min})$ and a sustained second phase (21-45 min) were observed in otherwise untreated islet grafts. Adding angiotensin II to the high-glucose medium during perfusion attenuated the first phase of glucose-stimulated insulin release, and also decreased insulin release early in the second phase (Fig. 5a). When losartan was added to the high-glucose medium, there was a markedly improved early phase of insulin release with a peak value more than double that in control grafts (Fig. 5b). In contrast, the second phase of insulin release was decreased in these acute losartan-treated grafts. Islet grafts obtained from transplanted animals subjected to losartan treatment throughout the 4-week post-transplantation period had a lower first and second phase of insulin release than control grafts. However, when losartan was administered orally during the final 14 days prior to measurements, the first phase of glucose-stimulated insulin release was increased while the second phase was decreased.

The insulin content in control islet grafts was $3,105 \pm 202$ ng insulin/graft $(n=8)$. Islet grafts in animals subjected to oral losartan treatment throughout the 4-week post-transplantation period or during the final 14 days before mea- surements had higher insulin contents $(4,568 \pm 211[n=8]$ and 5,051 $\pm 204 \mathrm{ng}$ insulin [ $n=8]$ respectively, $p<0.05$ in both cases) when compared with controls.

\section{Graft (pro)insulin and total protein biosynthesis}

Exposure to $1 \mu \mathrm{mol} / 1$ losartan did not affect (pro)insulin biosynthesis in retrieved islet grafts at high glucose concentrations $(16.7 \mathrm{mmol} / \mathrm{l} ; 512 \pm 83[n=7]$ and $550 \pm 95[n=8]$ $\mathrm{dpm} \cdot$ islet $\mathrm{graft}^{-1} \cdot 120 \mathrm{~min}^{-1}$ for control and losartan-exposed grafts respectively). Likewise, total protein biosynthesis in the islet grafts was not affected by losartan at the high glucose concentrations $(803 \pm 77$ and $936 \pm 231 \mathrm{dpm} \cdot$ islet graft $^{-1} \cdot 120 \mathrm{~min}^{-1}$ for control and losartan-exposed grafts respectively; $n=7$ in both groups).

\section{Discussion}

Several organs including the pancreas seem to have local RAS, where locally produced angiotensin II exerts local 


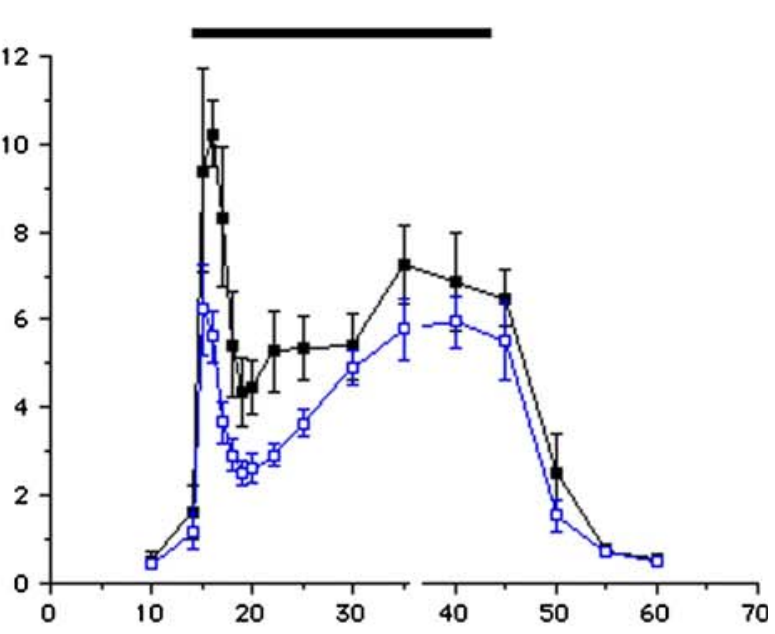

Time (min)

疍
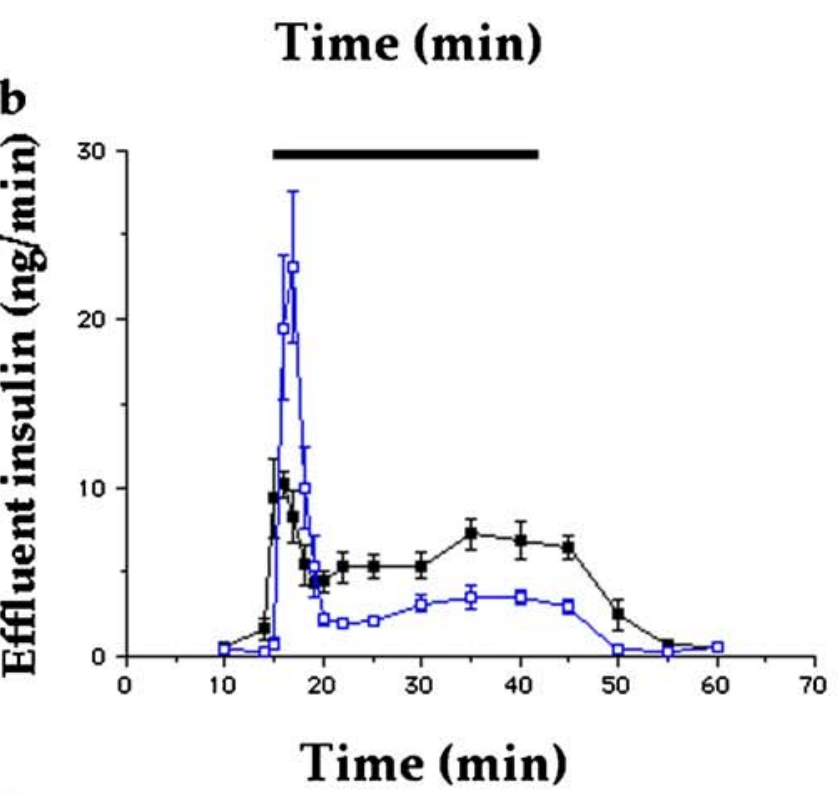

C

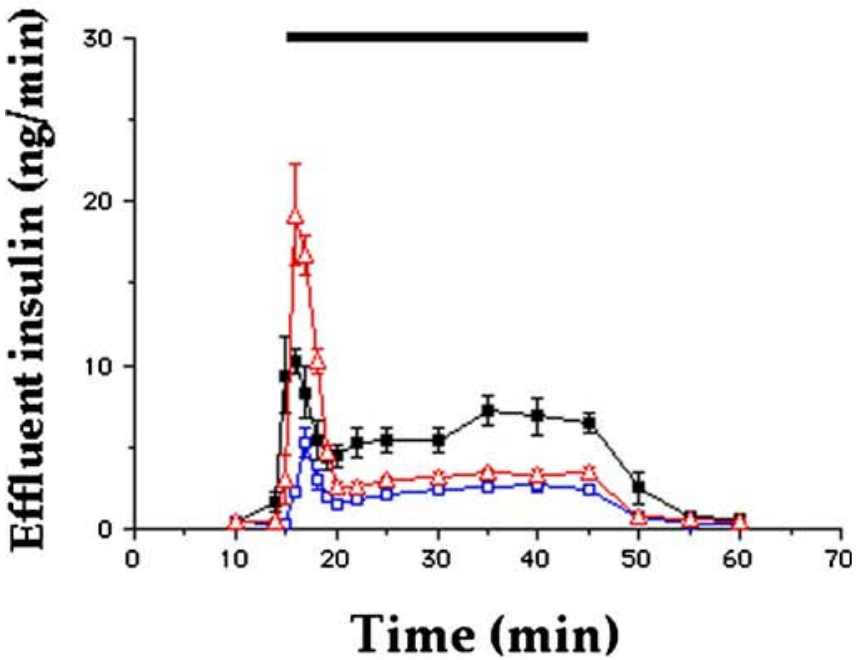

Fig. 5 Insulin concentrations in effluent medium collected from perfused islet-graft-bearing kidneys of C57BL/6 mice. After 15 min of perfusion with a medium containing $2.8 \mathrm{mmol} / \mathrm{l}$ D-glucose, insulin secretion was stimulated by a 30 -min period with $16.7 \mathrm{mmol} /$ $1 \mathrm{D}$-glucose (bar) followed by $15 \mathrm{~min}$ with $2.8 \mathrm{mmol} / \mathrm{l} \mathrm{D}$-glucose. In (a) the effect of adding angiotensin II (10 ng/ml; empty boxes) to the high-glucose medium was compared with the perfusion of control islet grafts (closed boxes). $p<0.05$ vs control grafts for all observations between 15 and $25 \mathrm{~min}$. In (b) the effect of adding the angiotensin II type 1 receptor inhibitor losartan $(100 \mu \mathrm{g} / \mathrm{ml}$; empty boxes) to the high-glucose medium was compared with the perfusion of control islet grafts (closed boxes). $p<0.05$ vs control grafts for all observations between 16 and $18 \mathrm{~min}$ and between 20 and 45 min. In (c) the effect of oral treatment with losartan throughout the post-transplantation period (days 0-28; empty boxes) or for the final 14 days (days 15-28; empty triangles) was compared with the perfusion of control islet grafts (closed boxes). $p<0.05$ vs control grafts for losartan days $0-28$ between 16 and $50 \mathrm{~min}$, for losartan days 15 28 between 16 and $18 \mathrm{~min}$, and for losartan days 15-28 between 20 and $45 \mathrm{~min}$. Please note that the same controls are used in $\mathbf{a}-\mathbf{c}$, but that the scales on the ordinates are different. All values are given as means \pm SEM for six to eight animals. $p<0.05$ vs control grafts. All comparisons were made using ANOVA

effects [17-24]. The best known functions of angiotensin II, e.g. cardiovascular effects, are mediated through the $\mathrm{AT}_{1}$ receptor [25]. The clinical use of RAS inhibitors in the treatment of hypertension and cardiac failure shows few adverse effects. On the contrary, mainly beneficial effects, such as reduced cardiovascular morbidity and mortality and reduced diabetes incidence, have been described [26]. Mouse pancreatic islets were recently shown to have a local RAS, which means that angiotensin II may be formed locally in high concentrations within the islets [11]. Moreover, the $\mathrm{AT}_{1}$ receptor for angiotensin II was markedly upregulated in islet transplants [11].

In previous studies of native islets, we observed that exogenous administration of angiotensin II may inhibit first-phase glucose-stimulated insulin release through vasoconstrictive effects [9]. The vasoconstrictive effects of angiotensin II in transplanted islets seemed even more pronounced than those in native islets, as previously observed [10]. In the present study, we found that the oxygenation and the first and second phases of glucosestimulated insulin release were decreased by angiotensin II in transplanted islets. Some of the effects of exogenously administered angiotensin II, especially on the second phase, may not just be related to vascular effects but may be direct negative effects on (pro)insulin biosynthesis, as recently reported [11].

Administration of an angiotensin-converting enzyme inhibitor or an angiotensin II receptor antagonist increases native islet blood flow two- to three-fold [9]. The present findings show that islet graft blood flow may be improved to a similar extent after blocking the $\mathrm{AT}_{1}$ receptor for angiotensin II. Most interestingly, the increase in islet graft blood perfusion improved the oxygen tension levels within the transplanted pancreatic islets and also augmented the first phase of glucose-stimulated insulin release. Thus, in contrast to in native islets [9], inhibiting the actions of endogenously formed angiotensin II in transplanted islets not only causes increased blood perfusion but also marked improvements in early insulin release. Such functional 
improvement has also recently been described in islets of the type 2 diabetic Zucker rat [27]. The improved first phase of glucose-stimulated insulin release in our experiments may be caused by direct effects of losartan on pancreatic beta cells, but this seems less likely in view of the fact that losartan, in our previous experiments in this strain [11], had no acute effects on glucose-stimulated insulin release, glucose oxidation or (pro)insulin biosynthesis in isolated islets. The latter finding was also confirmed for retrieved islet grafts in the present study. This raises the possibility that the low blood perfusion of transplanted islets normally restricts and delays the output of insulin to the systemic circulation. The lower insulin release in the second phase of losartan-exposed islet transplants would then be explained by a 'post-washout' effect. The improved first phase of glucose-stimulated insulin exocytosis may also be the result of the higher oxygenation of the islet beta cells, secondary to the higher blood perfusion. The normally low oxygenation of transplanted islets means that their metabolism tends to be much more anaerobic than that of endogenous islets, which results in lactate formation and tissue acidosis [28]. It is interesting to note that the kinetics of glucose-stimulated insulin secretion from the losartan-exposed islet grafts, with its distinct first peak, mimics the perfused mouse pancreas much more than control islet grafts $[29,30]$.

Notably, not only islet graft blood flow but also renal blood flow was increased by losartan in this study. Although the increase in renal blood flow was less pronounced, it suggests that the observed increase in islet graft blood flow is site dependent. Previous studies, however, strongly indicate that the blood flow regulation of islet grafts is independent of the implantation organ $[31,32]$.

Besides the well-known effects on vascular tonus, several studies implicate a role of local RAS in oxidative stress defence $[33,34]$ and in the regulation of angiogenesis [3538]. To evaluate the effect of islet RAS on the formation of a new islet vascular system after transplantation, losartan was, in some cases, added to the drinking water of newly transplanted animals. Losartan notably hindered the islet revascularisation process. The inhibitory effects of losartan on angiogenesis in the islet grafts seemed specific to the endocrine tissue. The difference between the endocrine and connective tissue is unlikely to be explained by the effect of losartan on angiogenesis, but may be a result of inhibiting the effects of locally formed islet angiotensin II. Notably, the grafts exposed to losartan throughout the 4-week posttransplantation period had decreased first and second phases of glucose-stimulated insulin release in perfusion experiments, despite a blood perfusion similar to that found in control grafts. This suggests that not only the level of islet graft blood flow but also the localisation of blood vessels in relation to the insulin-secreting beta cells is highly important for the insulin drainage. The insulin content in the pancreatic islets, chronically exposed to losartan, was higher than that in transplanted control islets, which may reflect improved oxidative stress defence with the survival of more islet cells. The lower proportion of connective tissue in islet grafts subjected to chronic losartan treatment most likely reflects inhibition of the pro-fibrotic properties of angiotensin II mediated through the $\mathrm{AT}_{1}$ receptor [39].

The reason for the seemingly increased importance of a local angiotensin-generating system in transplanted islets compared with in endogenous islets is unclear. However, at least in the exocrine pancreas, inflammatory conditions upregulate several components of the local RAS [40]. Moreover, high local expression of angiotensin II may be maintained or even upregulated by chronically low levels of oxygen tension [33,41], which seem to occur in islet grafts [42].

In conclusion, this study shows that inhibition of the local islet RAS may be a feasible strategy to increase blood perfusion, oxygen tension and function within islet grafts. Indeed, the impairments in the islet graft vascular system seem to be a combination of anatomical failure with low vascular density, and functional failure with inappropriately low blood perfusion.

Acknowledgements A. Nordin, B. Bodin, E. Törnelius and E. Wahlund are gratefully acknowledged for their technical assistance. We also thank K. Wester for highly useful advice concerning histochemistry. The study was supported by grants from the Swedish Research Council (72XD-15043), the Juvenile Diabetes Research Foundation, the Swedish Diabetes Association, the Swedish Juvenile Diabetes Fund, the Åke Wiberg Foundation, the Anér Foundation, the Clas Groschinsky Memorial Fund, the Family Ernfors Fund, EFSD/NOVO and the Mainline Research Scheme from the Chinese University of Hong Kong (Ref. no.: MR00/008). Losartan was kindly provided by Merck \& Co.

\section{References}

1. Shapiro AMJ, Lakey JR, Ryan EA et al (2000) Islet transplantation in seven patients with type 1 diabetes mellitus using a glucocorticoid immunosuppressive regimen. $N$ Engl J Med 343:230-238

2. Ryan EA, Lakey JR, Rajotte RV et al (2001) Clinical outcomes and insulin secretion after islet transplantation with the Edmonton protocol. Diabetes 50:710-719

3. Jansson L (1994) The regulation of pancreatic islet blood flow. Diabetes Metab Rev 10:407-416

4. Menger MD, Jäger S, Walter P, Feifel G, Hammersen F, Messmer K (1989) Angiogenesis and hemodynamics of microvasculature of transplanted islets of Langerhans. Diabetes 38 (Suppl 1):199-201

5. Mendola JF, Goity C, Fernandez-Alvarez J et al (1994) Immunocytochemical study of pancreatic islet revascularization in islet isograft: effect of hyperglycemia of the recipient and of in vitro culture of islets. Transplantation 57:725-730

6. Sandberg J-O, Margulis B, Jansson L, Karlsten R, Korsgren O (1995) Transplantation of fetal porcine pancreas to diabetic or normoglycemic nude mice: evidence of a rapid engraftment process demonstrated by blood flow and heat shock protein 70 measurements. Transplantation 59:1665-1669

7. Carlsson P-O, Palm F, Andersson A, Liss P (2001) Markedly decreased oxygen tension in transplanted rat pancreatic islets irrespective of implantation site. Diabetes 50:489-495

8. Mattsson G, Jansson L, Carlsson P-O (2002) Decreased vascular density in mouse pancreatic islets after transplantation. Diabetes 51:162-167

9. Carlsson P-O, Berne C, Jansson L (1998) Angiotensin II and the endocrine pancreas: effects on islet blood flow and insulin secretion in rats. Diabetologia 41:127-133 
10. Olsson R, Jansson L, Andersson A, Carlsson P-O (2000) Local blood flow regulation in transplanted rat pancreatic islets: influence of adenosine, angiotensin II, and nitric oxide inhibition. Transplantation 70:280-287

11. Lau T, Carlsson P-O, Leung PS (2004) Evidence for a local angiotensin-generating system and dose-dependent inhibition of glucose-stimulated insulin release by angiotensin II in isolated pancreatic islets. Diabetologia 47:240-248

12. Andersson A (1978) Isolated mouse pancreatic islets in culture: effects of serum and different culture media on the insulin production of the islets. Diabetologia 14:397-404

13. Carlsson P-O, Jansson L, Östenson C-G, Källskog Ö (1997) Islet capillary blood pressure increase mediated by hyperglycemia in NIDDM GK rats. Diabetes 46:947-952

14. Carlsson P-O, Liss P, Andersson A, Jansson L (1998) Measurements of oxygen tension in native and transplanted rat pancreatic islets. Diabetes 47:1027-1032

15. Korsgren O, Jansson L, Andersson A (1989) Effects of hyperglycemia on the function of isolated mouse pancreatic islets transplanted under the kidney capsule. Diabetes 38:510-515

16. Halban PA, Wollheim CB, Blondel B, Renold AE (1980) Longterm exposure of isolated pancreatic islets to mannoheptulose: evidence for insulin degradation in the B-cell. Biochem Pharmacol 29:2625-2633

17. Chappell MC, Millsted A, Diz DI, Brosnihan KB, Ferrario CM (1991) Evidence for an intrinsic angiotensin system in the canine pancreas. J Hypertens 9:751-759

18. Wang Y, Yamaguchi T, Francosaenz R, Mulrow PJ (1992) Regulation of renin gene expression in rat adrenal zona glomerulosa cells. Hypertension 20:766-781

19. Phillips MI, Speakman EA, Kimura B (1993) Levels of angiotensin and molecular biology of the tissue renin-angiotensin systems. Regul Pept 43:1-20

20. Ghiani BU, Masini MA (1995) Angiotensin II binding sites in the rat pancreas and their modulation after sodium loading and depletion. Comp Biochem Physiol 111A:439-444

21. Vinson GP, Saridogan E, Puddefoot JR, Djahanbakhch O (1997) Tissue renin-angiotensin systems and reproduction. Hum Reprod 12:651-662

22. Leung PS, Chan HC, Wong PYD (1998) Immunohistochemical localization of angiotensin II in the mouse pancreas. Histochem J 30:21-25

23. Leung PS, Chan WP, Wong TP, Sernia C (1999) Expression and localization of the renin-angiotensin system in the rat pancreas. J Endocrinol 160:13-19

24. Tahmasebi M, Puddefoot JR, Inwang ER, Vinson GP (1999) The tissue renin-angiotensin system in human pancreas. J Endocrinol 161:317-322

25. Burnier M (2001) Angiotensin II type 1 receptor blockers. Circulation 103:904-912

26. Dahlöf B, Devereux RB, Kjeldsen SE et al (2002) Cardiovascular morbidity and mortality in the Losartan Intervention For Endpoints reduction in hypertension study (LIFE): a randomised trial against atenolol. Lancet 359:995-1003

27. Tikellis C, Wookey PJ, Candido R, Andrikopoulos S, Thomas MC, Cooper ME (2004) Improved islet morphology after blockade of the renin-angiotensin system in the ZDF rat. Diabetes 53:989-997
28. Carlsson P-O, Nordin A, Palm F (2003) pH is decreased in transplanted rat pancreatic islets. Am J Physiol Endocrinol Metab 284:E499-E504

29. Jamen F, Persson K, Bertrand G et al (2000) PAC1 receptordeficient mice display impaired insulinotropic response to glucose and reduced glucose tolerance. J Clin Invest 105:13071315

30. Maechler P, Gjinovci A, Wollheim CB (2002) Implication of glutamate in the kinetics of insulin secretion in rat and mouse perfused pancreas. Diabetes 51(Suppl 1):S99-S102

31. Jansson L, Sandler S (1990) Altered blood flow regulation in autotransplanted pancreatic islets of rats. Am J Physiol Endocrinol Metab 259:E52-E56

32. Jansson L, Sandler S (1992) The blood perfusion of transplanted pancreatic islets. Evidence for a maturation of the blood-flow response to D-glucose with time after implantation. Transplantation 53:1368-1369

33. Ip SP, Chan WY, Leung PS (2002) Effects of chronic hypoxia on the circulating and pancreatic rennin-angiotensin system. Pancreas 25:296-300

34. Dijkhorst-Oei LT, Stroes ES, Koomans HA et al (1999) Acute simultaneous stimulation of nitric oxide and oxygen radical by angiotensin II in humans in vivo. J Cardiovasc Pharmacol 33:420-424

35. Le Noble FA, Hekking JW, Van Straaten HW, Slaaf DW, Struijker Boudier HA (1991) Angiotensin II stimulates angiogenesis in the chorio-allantoic membrane of the chick embryo. Eur J Pharmacol 195:305-306

36. Le Noble FA, Schreurs NH, Van Straaten HW et al (1993) Evidence for a novel angiotensin II receptor involved in angiogenesis in chick embryo chorioallantoic membrane. Am J Physiol 264:R460-R465

37. Stoll M, Steckelings UM, Paul M, Bottari SP, Metzger R, Unger T (1995) The angiotensin AT2-receptor mediates inhibition of cell proliferation in coronary endothelial cells. J Clin Invest 95:651-657

38. Munzenmaier DH, Greene AS (1996) Opposing actions of angiotensin II on microvascular growth and arterial blood pressure. Hypertension 27:760-765

39. Ruperez M, Lorenzo O, Blanco-Colio LM, Esteban V, Egido J, Ruiz-Ortega M (2003) Connective tissue growth factor is a mediator of angiotensin II-induced fibrosis. Circulation 108: $1499-1505$

40. Leung PS, Chan WP, Nobiling R (2000) Regulated expression of pancreatic renin-angiotensin system in experimental pancreatitis. Mol Cell Endocrinol 166:121-128

41. Chan WP, Fung ML, Nobiling R, Leung PS (2000) Activation of local renin-angiotensin system by chronic hypoxia. Mol Cell Endocrinol 160:107-114

42. Carlsson P-O, Palm F, Andersson A, Liss P (2000) Chronically decreased oxygen tension in rat pancreatic islets transplanted under the kidney capsule. Transplantation 69:761-766 